\title{
The Effect of the Media Reporting of Terrorist Attacks on the Czech Travel Insurance Market between 2011-2016

\author{
Petra Budská*
}

\begin{abstract}
:
Media plays a significant part of our lives and it has the power to provide us with ideas and/or some perspective on the selected topics. Terrorist attacks cause fear which is spread by media. The fact is that during the biggest "terrorist fever" in the Czech Republic between 2015-2016, the number of terrorist attacks was paradoxically declining, and vice versa. The presented paper answers the question of how large is the effect of the media reporting of terrorist attacks on the number of travellers abroad and when - after how many quarters - the travellers' reaction follows. Based on the quarterly data of the number of travellers abroad and the gross premium written we found out that the media reporting of terrorist attacks is a significant variable and the decline in the number of travellers in some years represents the "loss of one quarter" of travellers. Using the panel data model, we found out that although the number of travellers abroad has declined, the gross premium written has increased. Higher growth as well as significance in terms of the gross premium written was recorded only for the sole specialist on travel insurance in the Czech Republic - the ERV European Insurance Company when compared with the travel insurance market as a whole.
\end{abstract}

Key words: Insurance Premium; Panel Data Models; Media; Terrorist Attacks.

JEL classification: C23, C29, G22, M39.

\section{Introduction}

The aim of the paper is to analyse the effect of terrorist attacks and their media coverage on the travel market, specifically on the number of people travelling abroad, and on the Czech travel insurance market during the period 2011-2016. Terrorist attacks are, without doubt, a stressful factor. Human behaviour cannot be generalised, it is individual, and, moreover, influence of the media on the fear of terrorist attacks is undeniable, the fear being written "more under skin" of ordinary citizens of the Czech Republic. There are numerous psychology papers, books and analyses on the triangle "Terrorist attacks-Media-Human behaviour" such as "The Role of Personal Experience in Contributing to Different Patterns of Response to Rare Terrorist Attacks"(Yechiam, Barron and Erev, 2015) or "What predicts

Petra Budská; University of Economics, Prague, Faculty of Finance and Accounting, Department of Banking and Insurance, W. Churchill Sq. 4, 13067 Prague 3, Czech Republic, <budp03@vse.cz>.

The article is processed as an output of a research project registered by the Grant Agency under the registration number VŠE IGS F1/21/2016. 
Budská, P.: The Effect of the Media Reporting of Terrorist Attacks on the Czech Travel Insurance Market between 2011-2016.

psychological resilience after a disaster? The role of demographics, resources, and life stress" (Bonanno et al., 2005). Some of the papers deal directly with the attacks of September 11, 2001, such as "What good are positive emotions in a crisis? A prospective study of residence and emotions following the terrorist attacks on the United States on September 11th, 2001" (Frederickson et al., 2003). We would like to investigate what "the numbers say" on this topic, specifically on the field of the Czech travel insurance market.

\section{Data and Methodology}

\subsection{Variables}

The number of terrorist attacks in 2011-2016 fluctuates, as shown in Figure 1, but only some of them were medialized in the Czech Republic, specifically those which have occurred in Europe and affected ordinary ${ }^{1}$ public life. The list of terrorist attacks in which we are interested is presented in Appendix 1.

\subsubsection{Number of terrorist attacks}

One of the basic variables reviewed in this paper is the number of terrorist attacks which show us how many attacks were recorded each year within our monitored period. The number represents those attacks which actually took place and those which were prepared but thwarted by national police units. As the source, we used Europol Annual Report on the Terrorism Situation and the Trend Report. The development of the first variable is recorded in Figure 1.

\section{Fig. 1 Number of terrorist attacks}

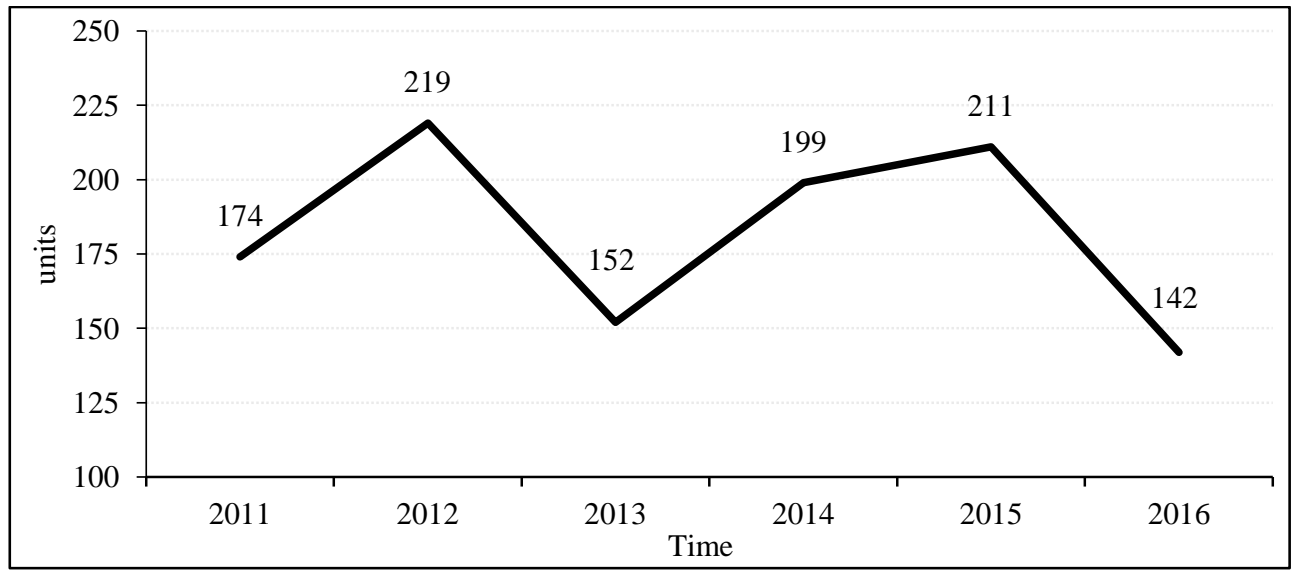

Source: Europol Europa, edited by the author.

1 Ordinary in the meaning that families were affected in their everyday activities (shopping, journeys to work, holidays, etc.). The attacks had also an impact on public life in being the part of the mainstream news (main broadcast) of public television. 


\subsubsection{Media reporting}

Media reporting is defined as the appearance of information on selected terrorist attacks in the media. It could be an article on a website, a TV spot during the prime broadcast time of public television, or newspapers. Each of the selected attacks, which are the subject of our research, had to occur at least once ${ }^{2}$ in all types of the mentioned media. That is, how the condition of media reporting is met.

\subsubsection{Number of travellers}

It is the number of all the Czech people who travelled abroad each year, regardless of whether for short or long journeys. Personal as well as business trips are included. Detailed statistics are available on the website of the Czech Statistical Office; the development is shown in Figure 2 below.

\section{Fig. 2 Number of travellers}

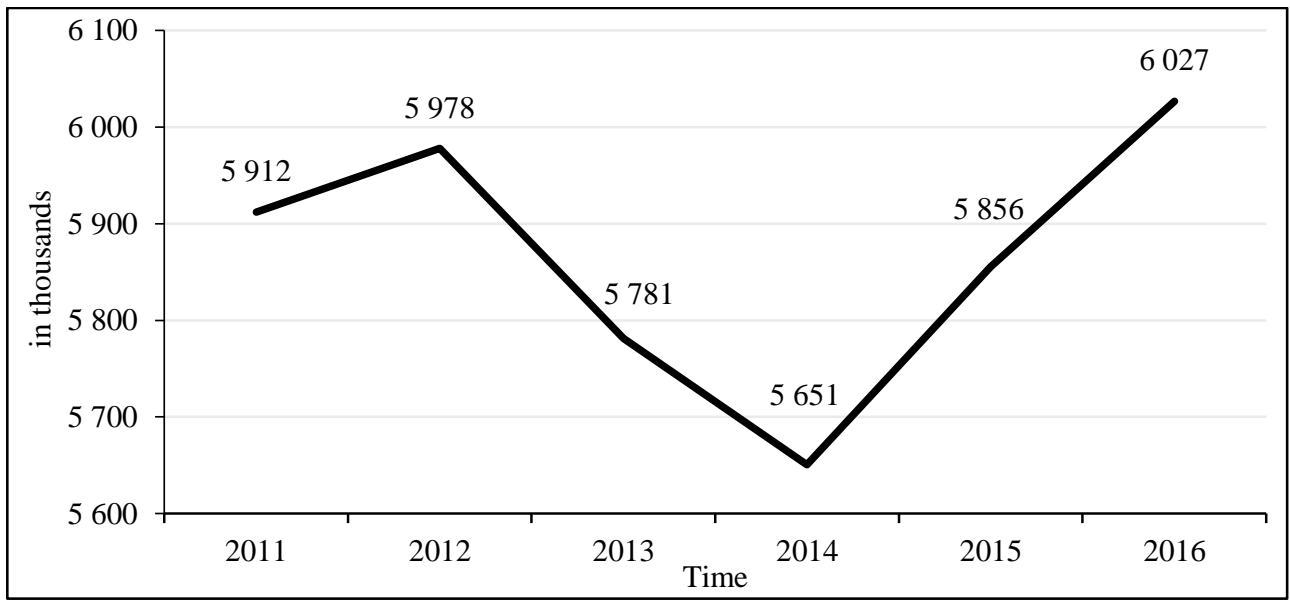

Source: Czech Statistical Office, edited by the author.

During the years of high media coverage of terrorist attacks in 2015 and 2016, we would expect a decrease in the number of people travelling abroad, but the trend is, in fact, quite opposite, as shown in Figure 2. From the year 2012, when the number of travellers almost reached the level of 6 million people, the variable decreased for 2 years and reached its minimum in 2014, when the travel market lost almost three hundred thousand travellers. Over the next two years, the variable reached its new peak - thirty thousand travellers above the six-million mark. The

2 All the mentioned attacks appeared in the media several times, but it would be difficult to count how many times and where. Moreover, it is not important for our research. Because of that, in the main text we laid down the condition of at least one appearance. We do not refer to any "hard-tofind" attacks, only to the condition of appearance. 
Budská, P.: The Effect of the Media Reporting of Terrorist Attacks on the Czech Travel Insurance Market between 2011-2016.

final data for 2017 were not available at the time of writing; nevertheless based on the data from the first three quarters we can state that the number of travellers will surpass the magical six-million-mark.

\subsubsection{Gross premium written}

We are interested especially in the gross premium written on the Czech travel insurance market in the cases where people decided to go abroad in terms whether they were willing to cover the travel risks more, less, or with no change. For comparison we provide data for the life insurance market and the whole non-life insurance market. The gross premium data were downloaded from the server of the Czech Insurance Association, which is an interest association of domestic commercial insurance companies. They form $98 \%$ of the Czech gross premium written, so from this point of view the data provide a representative sample for our research. Moreover, the Czech Insurance Association's data are used by Insurance Europe as the representative - official - data for the Czech Republic. Development of all the variables is shown in the following Figure 3 and 4.

\section{Fig. 3 Gross premium written}

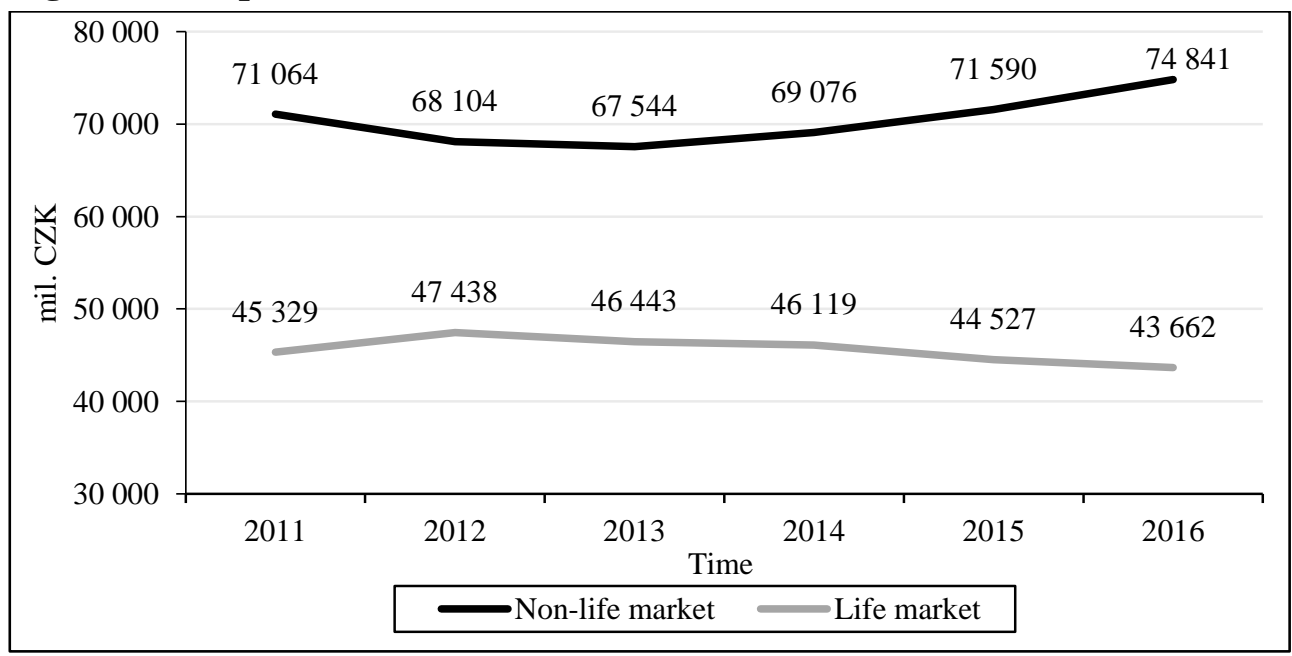

Source: Author based on the Czech Insurance Association.

The life and non-life insurance markets have the opposite development. In the case of a decrease in the non-life market, the life market records a moderate growth and vice versa, though the rate of growth is higher. Especially the growth between the years 2013 and 2016 raised the gross premium written by more than CZK 7 billion, of which only $14 \%$ counts towards travel insurance. Travel insurance is not the leader of the growth; nevertheless, its development is also worth mentioning. 
Travel insurance, which represents around $4.3 \%$ of the non-life market, shows no trend and fluctuates around CZK 2 billion during the monitored period. But the interesting fact is that a significant growth is recorded by the leader and the only specialist on travel insurance in the Czech Republic, the ERV European Insurance Company ${ }^{3}$. For comparison see Figure 4.

The company holds about $20 \%$ of the travel market and because of its privileged position; we added its gross premium written as an additional variable of our research.

\section{Fig. 4 Trends in gross premium written}

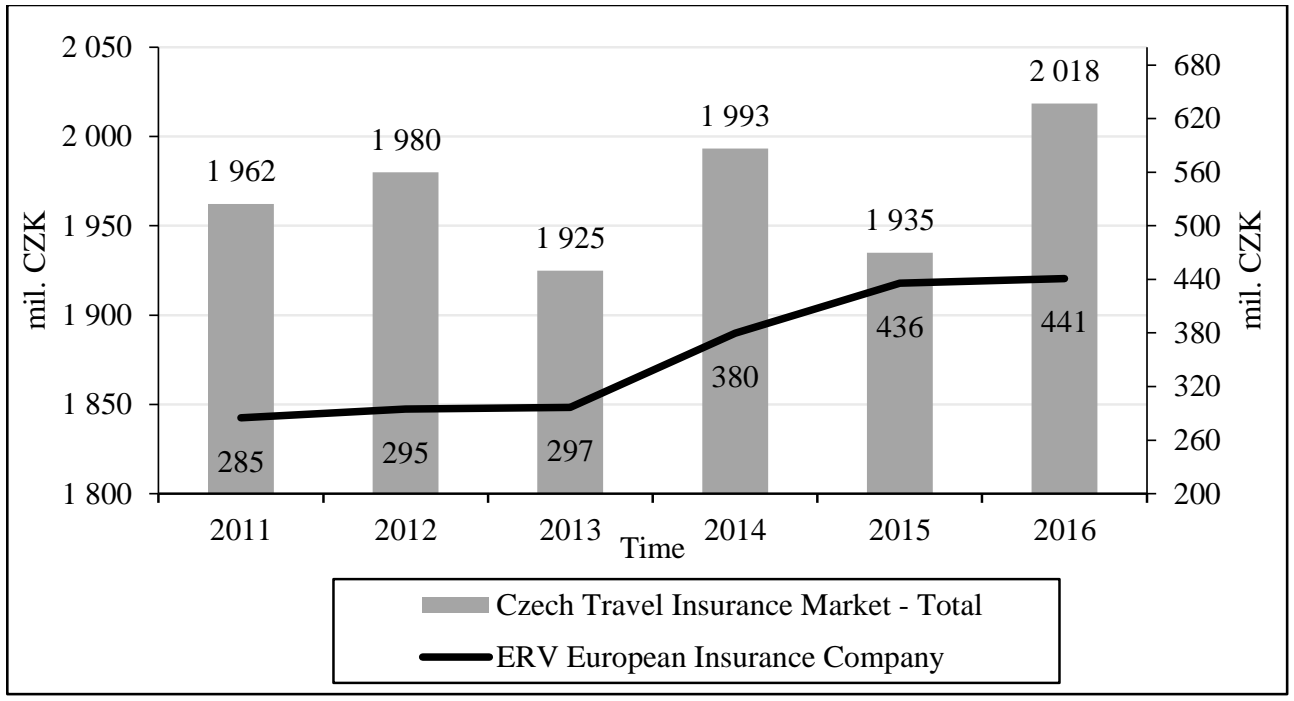

Source: Author based on the Czech Insurance Association.

\subsubsection{Macroeconomic variables}

Apart from the traditional and generally adopted macroeconomic variables such as gross domestic product, inflation rate or unemployment, we also use specific variables such as the average nominal wage or exchange rate which were selected with respect to our topic. The development of all macroeconomic variables in the Czech Republic is shown in Table 1.

3 Hereinafter: ERV = ERV European Insurance Company. 
Budská, P.: The Effect of the Media Reporting of Terrorist Attacks on the Czech Travel Insurance Market between 2011-2016.

Tab. 1 Macroeconomic variables

\begin{tabular}{|c|c|c|c|c|c|c|c|c|}
\hline Variable & $\begin{array}{l}\text { Model's } \\
\text { Index }\end{array}$ & Unit & 2011 & 2012 & 2013 & 2014 & 2015 & 2016 \\
\hline $\begin{array}{l}\text { Gross } \\
\text { Domestic } \\
\text { Product }\end{array}$ & GDP & $\mathrm{CZK}$ bn. & 4,034 & 4,060 & 4,098 & 4,314 & 4,586 & 4,773 \\
\hline Inflation Rate & Inflation & $\%$ p.a. & 1.9 & 3.3 & 1.4 & 0.4 & 0.3 & 0.7 \\
\hline $\begin{array}{l}\text { Long-Term } \\
\text { Interest Rate }\end{array}$ & Rate & $\%$ p.a. & 3.7 & 2.8 & 2.1 & 1.6 & 0.6 & 0.4 \\
\hline Exchange Rate & Ex Rate & CZK/EUR & 24.6 & 25.1 & 26.0 & 27.5 & 27.3 & 27.0 \\
\hline $\begin{array}{l}\text { Unemployment } \\
\text { Rate }\end{array}$ & Unempl & $\%$ p.a. & 6.7 & 7.0 & 7.0 & 6.1 & 5.1 & 4.0 \\
\hline $\begin{array}{l}\text { Average } \\
\text { Nominal Wage }\end{array}$ & $\begin{array}{l}\text { Nom. } \\
\text { Wage }\end{array}$ & $\mathrm{CZK}$ & $\begin{array}{r}24,45 \\
5\end{array}$ & $\begin{array}{r}25,06 \\
7\end{array}$ & $\begin{array}{r}25,03 \\
5\end{array}$ & $\begin{array}{r}25,76 \\
8\end{array}$ & $\begin{array}{r}26,59 \\
1\end{array}$ & $\begin{array}{r}27,57 \\
5\end{array}$ \\
\hline
\end{tabular}

Source: Author based on the Czech Statistical Office.

Based on the data from Table 1, we can state that the Czech economy has been growing since 2013. We are witness to the expansion of the Czech economy and we wait for it to reach the peak and begin to overheat. In other words, the growth of gross domestic product is accompanied by a decrease in the rates of inflation and unemployment. This leads to a higher average nominal wage. The combination of these factors leads us to the notion that economic expansion together with higher average nominal wages prepares unrestricted conditions for deciding on how to spend money. ${ }^{4}$

It is also important to mention that our monitored period concludes in 2016 but based on the data from the first three quarters of 2017 and predictions of the Ministry of Finance of the Czech Republic, we can certainly state that the year 2016 does not represent the peak of the economic cycle. The Czech economy continues its growth.

\subsection{Hypotheses}

\section{Hypothesis 1}

The media reporting of terrorist attacks is a significant variable due to the number of people who travel abroad.

Moreover, we assume a negative relationship between the media reporting and the dependent variable - the number of travellers, although in Chapter 2.1 there is mentioned a clear increase in the number of travellers. It could be influenced by the quarterly data frequency and also by the fact that the effect of the media

4 GDP and the nominal wage growth with low inflation and almost zero level of interest rates (no attractive possibility of how to appreciate free funds) lead to a situation when people are willing to pay more for their insurance coverage. 
reporting can occur with a delay. Therefore, we use the cross-correlation coefficient to find out following how many quarters the impact is felt - referred to as the "shift". Because of the characterisation of terrorist attacks, we are interested in the movement forward".

Moreover, we assume panel data with fixed effects and verify the assumption with the F-test, the Breusch-Pagan test or the Hausman test, as appropriate (Baltagi, 2005).

The final model is described in Chapter 3.1.

\section{Hypothesis 2}

The media reporting of terrorist attacks has a significant impact on the Czech travel insurance market.

In hypothesis 2 we focus on the travel insurance market as a whole, but also on the previously mentioned ERV European Insurance Company as the only specialist in travel insurance. Using the cross-correlation coefficient, we determine the correct "shift" of the impact used for the model. Finally, we estimate the beta coefficient of the explanatory variable. The result for the cross-correlation coefficient is available in Appendix 2; the final model is described in Chapter 3.2.

\subsection{Data}

Table 2 provides an overview of the explanatory variables we use in our research.

\section{Tab. 2 Explanatory variables}

\begin{tabular}{ll}
\hline Explanatory Variable & Model's Index \\
\hline Gross Domestic Product & gdp \\
Inflation Rate & inflation \\
Long-Term Interest Rate & rate \\
Exchange Rate & ex_rate \\
Unemployment Rate & unempl \\
Average Nominal Wage & nom_wage \\
Number of Terrorist Attacks & t_attacks \\
Gross Premium Written of Travel Market & gpw_tm \\
Gross Premium Written of ERV European & gpw_erv \\
Insurance Company & travellers \\
Number of Residents Travelled Abroad &
\end{tabular}

Source: Author.

5 The cross-correlation coefficient can measure the impact for both sides (forward and back). 
The dataset covers the period 2011-2016 with a quarterly frequency. We have to point out that in 2013, the Czech Statistical Office has finished publishing the number of business travellers with a quarterly frequency and now it publishes these data only on the annual basis. Because of that, the time series from 2014 is slightly distorted. On the other hand, business travellers do not cover a significant part of the dataset and thus we have not adjusted them. But we will take this fact into account at the moment of the result's interpretation. We could have solve this issue by using all the dataset with annual frequency, but this is not possible because of the relatively short potential time series and because of the assumption that the impact of terrorist attacks is shorter. Because of that, we have decided to work with the quarterly frequency.

We also have to mention that at the time of writing, data for the 2017 have not yet been published. Nevertheless, for the analysis of the impact we also use real data from Q1 2017 to Q3 2017 and we do not use any estimation.

Moreover, the gross premium written on the travel market is published annually by the Czech Insurance Association and because of that we have to work with the quarterly frequency. Due to the fact that the travel insurance covers only $4.6 \%$ of the total market, we cannot use the data for the whole non-life market. The data were thus calculated from the Czech Insurance Association's quarterly reports as follows.

From the total gross premium written on the non-life market we deducted the largest categories, which are: vehicle liability insurance, accident insurance, business and retail insurance. We deducted about $75 \%$ of the non-life market. The remaining $25 \%$ were used to find the weights for the individual quarters according to which we split the annual travel market.

\subsection{Methodology}

From the structure of the dataset it is obvious that it corresponds with the panel data. It is a multilevel system of equations where variables are observed in time sequences. It is a combination of the time series (with the length $\mathrm{T}$ ) and crosssectional data (their number is $\mathrm{m}$ ).

We observe the same variables / objects (travel insurance market, the ERV European Insurance Company, etc.) in time, so for each quarter (since we use quarterly data frequency) we obtain values of individual variables and we can see their development. This structure is called the panel (Novák, 2007). Observations in the panel have a similar / common characteristic (market information) which they keep in time. Because of that, we say that the observations are dependent in time. If the characteristic is not significant, observations behave as independent variables. In this case we say that the dataset leaves the panel structure and it is called "pooled data". 
For our research, we have to decide if we will work with the panel data with fixed effects or with random effects, or if the individual effects of variables (the characteristic mentioned above) and the time structure are not significant and the data leave the panel structure and we adopt the standard ordinary least square method for the coefficients' estimation (Cipra, 2008). In this case we work with the data structure called "pooled data" as described above.

Because the value of $\mathrm{T}$ is quite low, $\mathrm{T}=24$ (6 years with quarter frequency) and the selected variables which hold the Czech market information, we assume to use the panel data with fixed effects or the pooled data. Due to the quarterly frequency and low value of $\mathrm{T}$ we assume as the best model the pooled data model. Our idea will be confirmed by the F-test and in the case of necessity by the LM test or the Hausman test.

In case we cannot reject the null hypothesis of the F-test, we confirm our assumption of using the pooled data, meaning that observations are independent in time. Otherwise our dataset structure corresponds with the panel data with fixed effects. In this case, we would confirm it by the Hausman test, where the null hypothesis is represented by the panel data with random effects against the alternative one - the panel data with fixed effects. The LM test is used to decide between the pooled data as the null hypothesis and the panel with random effects as the alternative one. Due to the low number of observations, the panel data with random effects is highly unlikely.

The variable of media reporting is used in the model as a dummy variable. If in the given quarter there occurs a terrorist attack (which we take as significant for our model and which is listed in Appendix 1), we work with the value of 1, otherwise with the value of 0 .

\section{Results and Discussion}

\subsection{Hypothesis 1}

Using the cross-correlation coefficient, we found out that terrorist attacks and the number of travellers are negatively correlated and their "shift" corresponds to one quarter (+1). It means that the travellers' reaction is reflected on the market within the next quarter (if the terrorist attack occurs in Q1, the reaction is reflected in Q2). The number of terrorist attacks and other variables remain unchanged, we consider the time t. The result is presented in Appendix 2

We are interested in two pieces of information. The first one is the result of the Ftest, where we test the null hypothesis which represents the use of the "pooled OLS" (independent observations) against the alternative one which represents the use of the panel data with fixed effects (Baltagi, 2005). Because the p-value is high, we cannot reject the null hypothesis on the $5 \%$ level of significance (as well 
Budská, P.: The Effect of the Media Reporting of Terrorist Attacks on the Czech Travel Insurance Market between 2011-2016.

as on the $1 \%$ level of significance) and we calculate the model again. As the best model we found the "pooled OLS" model shown below in Table 3; the model's tests are presented in Appendix 3.

\section{Tab. 3 Pooled OLS model, hypothesis 1, dependent variable - travellers}

\begin{tabular}{lrrrc}
\hline & Coefficient & Std. Error & t-ratio & p-value \\
\hline Const & 11,020 & 2,859 & 3.8545 & $0.0014 * * *$ \\
gpw_tm_1 & 1.5558 & 0.8699 & 1.7884 & $0.0927 *$ \\
gpw_erv_1 & 36.3510 & 5.3930 & 6.7405 & $<0.0000 * * *$ \\
gdp & 0.0118 & 0.0030 & 3.9437 & $0.0012 * * *$ \\
nom_wage & -0.9895 & 0.1916 & -5.1639 & $0.0001 * * *$ \\
dummy & -592.0930 & 291.3250 & -2.0324 & $0.0591 *$ \\
t_attacs & -29.8475 & 14.9341 & -1.9986 & $0.0629 *$ \\
inflation & 401.0970 & 128.1940 & 3.1288 & $0.0065 * * *$ \\
\hline
\end{tabular}

Source: Author based on the statistical software Gretl.

As a positive result in the final model for hypothesis 1, we note the significance of the dummy variable, which reflects the occurrence of selected medialized terrorist attacks, although the significance is not too high. Surprisingly, among the significant variables we have also found, except for macroeconomic variables, also the gross premium written on the total travel market and the number of terrorist attacks. We did not expect their significance because there was no clear trend, see Chapter 2.1 Variables. The gross premium written of the ERV together with the average nominal wage, gross domestic product and inflation are highly significant.

It is interesting to point out that a more significant variable from the perspective of the gross premium written is the gross premium written by the only specialist on the travel market. The estimated coefficient of both variables is positive which means the direct proportion with the number of travellers. A higher absolute value of the coefficient and higher influence can be seen in the variable of the ERV.

The ERV represents on average almost $20 \%$ of the travel insurance market, the rest of the market is represented by multi-line insurance companies for which travel insurance is minor and supplementary part of their portfolio. We can say that the rest of the market is "fragmented". Due to the fact that the fragmented part represents $80 \%$, we would expect as more significant the variable of the whole travel insurance market, but the result is opposite.

Moreover, multi-level insurance companies reduce their significance in the model because of co-operation with the banking sector. They basically use the banking 
sector as one of their distribution channels which help them to attract new clients for their core business.

The model has confirmed the tested hypothesis that the number of travellers has declined because of the higher media reporting of terrorist attacks. The corresponding coefficient is $\beta=-592.093$ which means that with the media reporting of terrorist attacks, the number of travellers has declined by almost six hundred thousand. The drop, illustrated by the black constant line in Figure 5, is in some years as much as one quarter. For comparison, again see Figure 5.

\section{Fig. 5 Travellers vs. downturn}

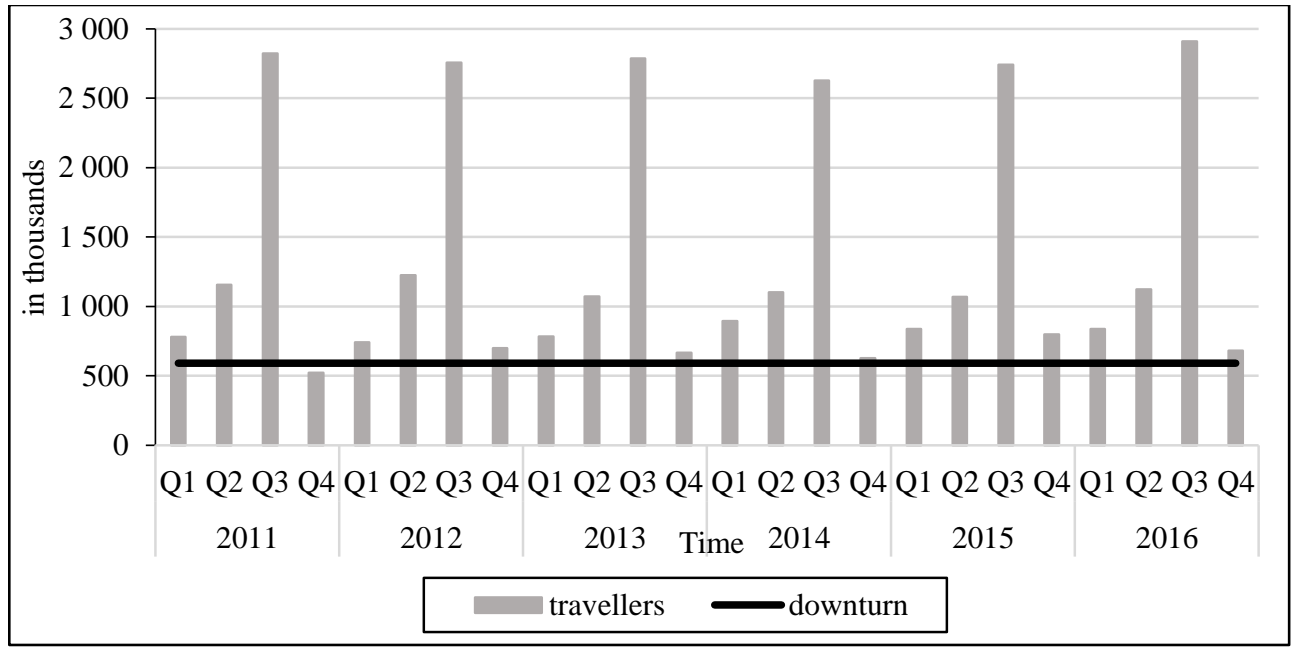

Source: Author based on the results.

The drop reflects, with unchanged pricing policy, the decrease in the gross premium written on the travel insurance market and can have impacts to the calculations of actuaries. Fortunately, the volume of lost clients (travellers) corresponds with the Q1 or Q4, i.e. out of the main season.

As for other interesting results, we can mention the $\beta$ coefficient of the average nominal wage (hereinafter referred to as wage). The simple assumption would be that with higher wages more people travel abroad for the simple reason that they have enough money to travel. But we see the opposite here, with a higher wage the number of travellers declines and conversely, with a lower wage the number of travellers grows. The absolute value of the coefficient is not overly high, meaning we talk about hundreds of travellers, but it is nevertheless an interesting phenomenon.

Because of the lack of information on where people travel and how expensive their journeys are, we cannot say if people with higher wages prefer to save money for a more expensive trip or purchase goods and services which were previously rare or 
luxury and therefore they travel less. On the other hand, people with lower wages can have motivation to maintain their social status or simply travel at a lower cost, but the reasons for travelling are always business or pleasure. We can find a number of explanations, but with no additional data we are unable to be more accurate. We would like to repeat the main finding that the media reporting of terrorist attacks is a significant variable and hypothesis 1 is thus not rejected. As for other interesting variables, we see the gross premium written on the whole travel market as well as the only market specialist. They are examined in hypothesis 2 below.

The whole model reaches a respectable descriptive value of about $79 \%$ according to R-square, respectively $69 \%$ according to Adjusted R-square, which we consider as a quite good result.

\subsection{Hypothesis 2}

The media reporting of terrorist attacks has a significant impact on the gross premium written on the whole travel insurance market.

In hypothesis 2, we focus on the whole travel insurance market as well as on the only specialist on the market, the ERV European Insurance Company.

Both sub-models were estimated in the same way as in the case of the model in hypothesis 1 . The sub-model 1 (gross premium written on the whole travel insurance market as the dependent variable) came out as insignificant and because of that, the results are not presented. The result of the sum-model 2 (gross premium written by the ERV as the dependent variable) is presented below.

In the case of the sub-model 2, we found out that the highest influence - "shift" is not in the first quarter (the reaction of travellers on the terrorist attack will not occur within the next quarter) but in the fourth quarter instead (meaning after one year). This can be explained as follows. Travel insurance is largely a seasonal matter and moreover, according to the ERV's annual reports, tour operators and travel agencies are the most important business partners. ERV co-operates with the majority of them, so the reaction to terrorist attacks can appear after a year when clients - travellers - reconsider their holidays.

The result of the best model of the sub-model 2 is presented below in Table 4; the model's tests are available in Appendix 3. 
Tab. 4 Pooled OLS model, hypothesis 2, dependent variable - gpw_erv

\begin{tabular}{lrrrc}
\hline & Coefficient & Std. Error & t-ratio & p-value \\
\hline Const & 300.975 & 171.619 & 1.754 & $0.0975 *$ \\
travellers_4 & 0.0085 & 0.0037 & 2.295 & $0.0347 * *$ \\
ex_rate & 12.8897 & 5.1521 & 2.502 & $0.0229 * *$ \\
dummy & 12.8085 & 9.5343 & 1.343 & 0.1968 \\
gpw_tm_4 & -0.0774 & 0.0189 & -4.088 & $0.0008 * * *$ \\
rate & -13.5292 & 5.7189 & -2.366 & $0.0301 * *$ \\
nom_wage & -0.0193 & 0.0034 & -5.650 & $<0.0001 * * *$ \\
\hline
\end{tabular}

Source: Author based on the statistical software Gretl.

The model is characterized as the pooled OLS model with a noticeable R-square value of about $86 \%$, respectively $82 \%$ for the Adjusted R-Square value, which is quite a high figure and close to the level of $90 \%$ above which the model is very good indeed. Unfortunately, the dummy variable in which we are interested is not significant. We continued in the analysis and following the removal of the (insignificant) dummy variable, we obtained the final model where significances and values of estimated coefficients and statistics of other variables were almost the same as in the model in Table 4. No more variables except for the dummy were removed.

The most significant variables are "both" as in hypothesis 1, the gross premium written and the wage, but with a small difference in that the gross premium written on the whole travel insurance market has a negative correlation in the sub-model 2, i.e. the estimated $\beta$ coefficient is negative.

\subsection{Further research}

As mentioned above, the majority of the ERV's business partners are tour operators and agencies, especially those ranking among the TOP 10. This means that terrorist attacks and their media coverage can influence more individual tour operators / agencies with respect to the destinations they focus on and considering how balanced is their "destination portfolio". Therefore, one possibility for further research is to evaluate the individual holiday destinations by the number of travellers / tourists. Another variable of interest is whether people prefer to travel domestically in their home country or whether they save for a holiday abroad.

Last but not least, yet another factor is the pricing policy of tour operators / agencies, air ticket sale companies or other participants on the travel market such as hotels or providers of alternative accommodation. Experience shows that during the period 2015-2016 we have witnessed some truly cheap "last minute" trips which from our point of view were "last minute under the price" offers. It was 
Budská, P.: The Effect of the Media Reporting of Terrorist Attacks on the Czech Travel Insurance Market between 2011-2016.

especially common for destinations where people were afraid to travel, such as Egypt. On the other hand, people were willing to pay y-o-y two or three times more for a similar trip, though to a "safe" destination.

\section{Conclusion}

In hypothesis 1 we focused on the issue of how the media reporting of terrorist attacks influences the number people travelling abroad. We conclude that the highest impact is recorded in the first quarter following the attack (respectively, its media reporting). Moreover, the dummy variable of the media reporting is significant in line with the expected development that with higher media reporting the travellers' numbers decline and the drop amounts to approximately six hundred thousand people, corresponding in some years to the whole first or fourth quarter (of the main season).

Other variables which affected the number of travellers include the average nominal wage (negative correlation) and from the gross premium written' s point of view, the position of the ERV European Insurance Company as the sole specialist on the Czech travel insurance market.

The second hypothesis confirms the higher significance of the ERV's position against the total Czech travel insurance market. The sub-model 2, where the dependent variable was represented by the ERV's gross premium written, showed that the media reporting of terrorist attacks is not significant in this case. The seasonal trend of travel insurance causes a greater impact than terrorist attacks. Another significant variable under evaluation was the average nominal wage. This can be explained by pricing policies of the travel market players or, alternatively, that people are willing to pay more for better services. However, it remains clear that the "driver" is not represented by terrorist attacks.

\section{References}

Annual Reports of the Czech Insurance Association. Available from: <www.cap.cz>. [22 March 2018].

Annual Reports of the ERV European Insurance Company. Available from: <www.ervpojistovna.cz>. [22 March 2018].

Baltagi, B., H., 2005. Econometric Analysis of Panel Data. John Wiley \& Sons Inc., Hoboken.

Bonanno, A., G., Galea, S., Bucciarelli, A., Vlahov, A., 20057. What predicts psychological resilience after disaster? The role of demographics, resources and life stress. Journal of Consulting and Clinical Psychology 2007, 75, 671-682. DOI: 10.1037/0022-006x.75.5.671.

Cipra, T., 2008. Finanční ekonometrie. Ekopress, Prague. 
Czech Statistical Office (CSU). Available from: <www.czso.cz>. [22 March 2018].

European Union Terrorism Situation and Trend Reports. Available from: <www.europol.europa.eu>. [22 March 2018].

Fredericson, B., L., Tugade, M., M., Waugh, C., E., Larkin, G., R., 2003. What good are positive emotions in crisis? A prospective study of residence and emotions following the terrorist attacks on the United States on September $11^{\text {th }}$, 2001. Journal of Personality \& Social Psychology 84, 365-376. DOI: 10.1037//0022-3514.84.2.365.

Macroeconomic Outlook of the Ministry of Finance of the Czech Republic. Available from: <www.mfcr.cz/cs/verejny-sektor/makroekonomika/makro ekonomicka-predikce>. [22 March 2018].

Novák, P., 2007. Analýza panelových dat. Acta Oeconomica PragensiaActa Oeconomica Pragensia 15, 71-78. DOI: 10.18267/j.aop.40.

Statistics of Insurance Europe. Available from: <www.insuranceeurope.eu>. [22 March 2018].

Yechiam, E., Barron, G., Erev. I., 20015. The role of personal experience in contribution to different patterns of response to rare terrorist attacks. Journal of Conflict Resolution 49, 430-439. DOI: 10.1177/0022002704270847. 
Budská, P.: The Effect of the Media Reporting of Terrorist Attacks on the Czech Travel Insurance Market between 2011-2016.

\section{Appendix 1: List of terrorist attacks}

Terrorist attacks are organized chronologically:

\section{1}

$22^{\text {nd }}$ of July - an attack by Norwegian right-side extremist in Oslo on government building, then liquidation majority of youth camp on Utoya Island.

\section{5}

$7-9^{\text {th }}$ of January - a shooting at the Paris headquarters of the satirical weekly newspaper Chalie Hedbo, a day after a shooting at the grocery store where died other people.

$13^{\text {th }}$ of November - a suicide bomber attacks in Paris in several places, concert hall Bataclan included.

\section{6}

$22^{\text {nd }}$ of March - a suicide attack at the Zaventem airport and Brussels metro.

$14^{\text {th }}$ of July - an attack by lorry in Nice, France.

$26^{\text {th }}$ of July - an attack on one of the churches in Normandy, the murder of serving priest.

$19^{\text {th }}$ of December - an attack by lorry on Christmas market in Germany, Berlin. 


\section{Appendix 2: Results for the hypothesis 1, 2}

Cross-correlation coefficient - hypothesis 1

\begin{tabular}{lccccccccccccc}
\hline LAG & $\mathbf{- 6}$ & $\mathbf{- 5}$ & $\mathbf{- 4}$ & $\mathbf{- 3}$ & $\mathbf{- 2}$ & $\mathbf{- 1}$ & $\mathbf{0}$ & $\mathbf{1}$ & $\mathbf{2}$ & $\mathbf{3}$ & $\mathbf{4}$ & $\mathbf{5}$ & $\mathbf{6}$ \\
\hline XCF & 0.06 & 0.05 & 0.01 & 0.06 & -0.07 & -0.04 & -0 & -0.04 & -0.01 & -0.02 & -0.02 & 0.05 & -0.03 \\
\hline
\end{tabular}

Cross-correlation coefficient - hypothesis 2 sub-model 1

\begin{tabular}{lccccccccccccc}
\hline LAG & $\mathbf{- 6}$ & $\mathbf{- 5}$ & $\mathbf{- 4}$ & $\mathbf{- 3}$ & $\mathbf{- 2}$ & $\mathbf{- 1}$ & $\mathbf{0}$ & $\mathbf{1}$ & $\mathbf{2}$ & $\mathbf{3}$ & $\mathbf{4}$ & $\mathbf{5}$ & $\mathbf{6}$ \\
\hline XCF & 0.31 & 0.05 & -0.03 & $-0.38^{*}$ & -0.34 & -0.02 & -0.01 & 0.31 & 0.25 & 0.07 & 0.01 & -0.05 & -0.13 \\
\hline
\end{tabular}

Cross-correlation coefficient - hypothesis 2 sub-model 2

\begin{tabular}{lccccccccccccc}
\hline LAG & $\mathbf{- 6}$ & $\mathbf{- 5}$ & $\mathbf{- 4}$ & $\mathbf{- 3}$ & $\mathbf{- 2}$ & $\mathbf{- 1}$ & $\mathbf{0}$ & $\mathbf{1}$ & $\mathbf{2}$ & $\mathbf{3}$ & $\mathbf{4}$ & $\mathbf{5}$ & $\mathbf{6}$ \\
\hline XCF & -0.01 & -0.02 & 0.08 & 0.12 & 0.11 & 0.07 & -0.035 & -0.039 & -0.11 & -0.17 & -0.23 & -0.18 & -0.21 \\
\hline
\end{tabular}


Budská, P.: The Effect of the Media Reporting of Terrorist Attacks on the Czech Travel Insurance Market between 2011-2016.

\section{Appendix 3: Models' tests}

Pooled OLS Model - hypothesis 1, dependent variable - travellers

\section{White's test for heteroskedasticity}

Null hypothesis: heteroskedasticity not present

Test statistic: $\mathrm{LM}=5.19504$

with $\mathrm{p}$-value $=\mathrm{P}($ Chi-square $(13)>5.19504)=0.970645$

\section{Test for normality of residual}

Null hypothesis: error is normally distributed

Test statistic: Chi-square $(2)=4.46378$

with p-value $=0.107325$

Pooled OLS Model - hypothesis 2, dependent variable - gpw_erv

\section{White's test for heteroskedasticity}

Null hypothesis: heteroskedasticity not present

Test statistic: $\mathrm{LM}=10.7118$

with $\mathrm{p}$-value $=\mathrm{P}($ Chi-square $(11)>10.7118)=0.467713$

\section{Test for normality of residual}

Null hypothesis: error is normally distributed

Test statistic: Chi-square $(2)=1.98134$

with p-value $=0.371328$

Durbin-Watson statistic $=\mathbf{1 . 3 5 0 1}$

p-value $=0.176425$ 